Drugs good, surgery better

Early surgical therapy for drugresistant temporal lobe epilepsy appears to be superior to drug treatment alone. A North American trial was halted early: 38 people were randomised, when the target was 200. At this stage, surgery was clearly superior at maintaining freedom from seizure at 2 years (11/15 with surgery vs $0 / 23$ without, $\mathrm{p}<0.001)$. However, care must be taken when looking at secondary endpoints. Controversially, the data and safety monitoring board (who halted the trial) blamed slow recruitment-but they also had access to unblinded outcome data.

JAMA 2012;307:922-30

\section{Susac's gift}

Dr John Susac passed away earlier this year at the age of 71 . To his colleagues he
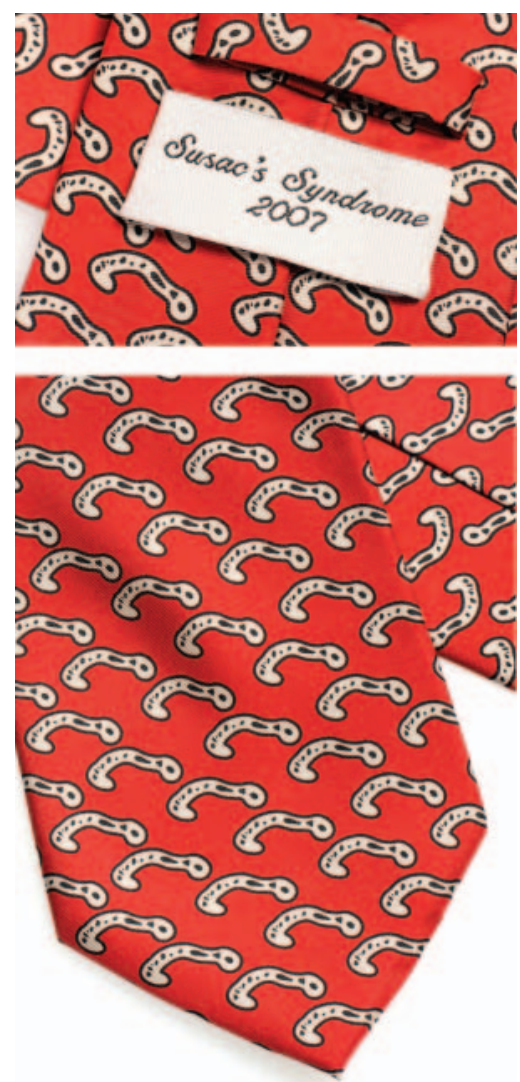

Figure1 Ubiquitous corpus callosum involvement in Susac's syndrome; as demonstrated by high resolution M R tie. will be remembered for his intellect and his compassion; to the world he will be remembered for his eponymous syndrome; and to a select few he will be remembered for his generosity. He made the effort to send a Susac's syndrome tie (figure 1) to any author whom he identified as writing about the said syndromeincluding a current editor of Practical Neurology.

Pract Neurol 2008;8:370-7

\section{Catastrophe}

A Fo Ben is grateful to Private Eye for identifying an unusual case of asphyxiation, which is best told verbatim. 'Her hands were covered in scratches and her pet cat was found disembowelled in the kitchen with its tail hacked off. On autopsy, her stomach was found to be full of cat intestines, adipose tissue, and strips of furcovered skin. An intact left kidney and adipose tissue were found lodged in her throat just above her epiglottis.' Who doesn't have a report of 'an unusual case of smothering secondary to ingesting raw pet cat' which they'd like to see in print?

Am J Forensic Med Pathol 2011;32:190-2

\section{In the eye of the beholder}

For patients losing their sight, few treatment options existed. Now, a new treatment combining cutting-edge technology and the skill of ophthalmic surgery may offer a way to some form of vision. A team from Oxford and King's College London are running the UK arm of an on-going trial implanting microchips onto the retina of patients with retinitis pigmentosa. The first patients have now had chips successfully implanted; although their vision should continue to improve as the brain adapts to the new visual inputs, the first patient has already improved from no sight at all before surgery to being able to identify a plate on a table. A light at the end of the tunnel, perhaps?

www.ox.ac.uk/media/news_stories/2012/ 120503.html

\section{Consequences of concussions}

Many children and young adults suffer from 'mild' concussions when playing contact sports at school and university. Although the effects of repeated, serious concussion have long been understood, questions have been raised about the long-term impact of these milder episodes. In a recent study, De Beaumont and colleagues investigated learning ability and the potential for plasticity in 13 university sports-players who had a history of concussions and 19 who did not. Those who had had concussions were less able to learn a novel motor task than the controls. Also, intrinsic plasticity within the motor cortex, as assessed by transcranial magnetic stimulation, was significantly reduced. The authors suggest that these findings may reflect altered $\gamma$-aminobutyric acid transmission, and raise some important questions about how benign these events are.

Cereb Cortex 2012;22:112-21

\section{Teaching the black dog old tricks?}

The hallucinogenic qualities of 'magic' mushrooms (Psilocybe semilanceata) were first documented in the medical literature in 1799. Their use was subsequently investigated as an adjunct to psychotherapy in the 1960 s, with some hints at their efficacy. Since their outlaw in most countries, research into their potential use has been difficult if not impossible-hindered both by strict governmental controls and the absence of previous literature on electronic search engines. Recently, two articles using functional MRI to investigate the potential use of psilocin (the psychoactive ingredient) have demonstrated significant changes in activity in brain regions involved in depression and anxiety. Although interpretation of these results is complex as the vasoactive properties of psilocin affect the functional MRI signal, behavioural data suggest the possibility of mushroom risotto as a treatment for depression.

Br J Psych 2012;200:238-44

Proc Natl Acad Sci 2012;109:2138-43 